\title{
Traumatic Diaphragmatic Hernia
}

National Cancer Institute

\section{Source}

National Cancer Institute. Traumatic Diaphragmatic Hernia. NCI Thesaurus. Code C34688.

The protrusion of abdominal cavity contents into the thoracic cavity via a hole in the diaphragm, which was acquired via a traumatic etiology. 